Sociohistórica, n 42, e066, 2do. Semestre de 2018. ISSN 1852-1606

Universidad Nacional de La Plata.

Facultad de Humanidades y Ciencias de la Educación.

Centro de Investigaciones Socio Históricas

\title{
De "víctimas inocentes" a jóvenes militantes
}

\author{
Reseña de Raggio, S. (2017). Memorias de la Noche de los \\ Lápices: Tensiones, variaciones y conflictos en los modos de \\ narrar el pasado reciente. La Plata: Universidad Nacional de \\ La Plata. Facultad de Humanidades y Ciencias de la \\ Educación; Posadas: Universidad Nacional de Misiones; Los \\ Polvorines: Universidad Nacional de General Sarmiento. \\ (Entre los libros de la buena memoria; 10)
}

María Ximena Gonzalez Iglesias

Universidad Nacional de General Sarmiento, Argentina gonzaleziglesiasximena@gmail.com

Cita recomendada: Gonzalez Iglesias, M. X.(2018). De "víctimas inocentes" a jóvenes militantes [Revisión del libro Memorias de la Noche de los Lápices: Tensiones, variaciones y conflictos en los modos de narrar el pasado reciente de Sandra Raggio]. Sociohistórica, 42, e066. https:// doi.org/10.24215/18521606e066

Recibido: 21 marzo 2018 - Aceptado: 30 abril 2018 - Publicado: 3 diciembre 2018 


\section{De "víctimas inocentes" a jóvenes militantes}

Reseña de Raggio, S. (2017). Memorias de la Noche de los Lápices: Tensiones, variaciones y conflictos en los modos de narrar el pasado reciente. La Plata: Universidad Nacional de La Plata. Facultad de Humanidades y Ciencias de la Educación; Posadas: Universidad Nacional de Misiones; Los Polvorines: Universidad Nacional de General Sarmiento. (Entre los libros de la buena memoria; 10)

Maria Ximena Gonzalez Iglesias

Universidad Nacional de General Sarmiento, Argentina

gonzaleziglesiasximena@gmail.com

El libro Memorias de la noche de los lápices. Tensiones, variaciones y conflictos en los modos de narrar el pasado reciente, forma parte de la colección "Entre los libros de la Buena Memoria" alentada por las Universidades Nacionales de La Plata, Misiones y General Sarmiento con el objetivo de difundir trabajos de investigación originales e inéditos, producidos en el seno de universidades nacionales y otros ámbitos académicos, centrados en temas de historia y memoria del pasado reciente. Producto de su tesis de maestría, Sandra Raggio presenta su indagación sobre las narrativas en torno a las memorias de "La noche de los lápices".

Esta investigación se inscribe en el campo de estudios de la historia de la memoria -que en los últimos años no ha cesado de expandirse-. Desde allí se promueve una perspectiva en la cual el recuerdo y el olvido no son considerados como procesos lineales en el tiempo, sino más bien como procesos dinámicos, cuya presencia responde a una compleja trama social, cultural y política, tal como sostiene Elizabeth Jelin. En este sentido, esta obra persigue el propósito de rastrear los procesos de selección, de recuerdo-olvido asociados a los usos del pasado en el ejercicio de la rememoración, en este caso de uno de los acontecimientos más emblemáticos del terrorismo de Estado.

Con los consabidos riesgos metodológicos que devienen de estudiar esa delicada porción del pasado, la autora realiza una minuciosa y rigurosa aproximación, a la vez, histórica y crítica sobre los procesos dinámicos y sociales desde los cuáles las memorias y los relatos se construyen, se disputan y se imponen unos por sobre otros.

Valiéndose del análisis de numerosas fuentes -oficiales, judiciales, escritas y orales-, la autora logra presentar un exhaustivo entramado de significados y sentidos asignados en las distintas formas de narrar un proceso tan complejo como doloroso. Con sobrados argumentos logra penetrar, de este modo, en las pretendidas verdades, cerradas y cristalizadas que se han ido conformando - en tanto discursos e imágenesdesde la recuperación de la democracia hasta nuestros días.

De este modo, el trabajo representa, además de un aporte al campo, una provocación de más amplio alcance para repensar nuestro incómodo presente.

El libro cuenta con un prólogo realizado por la prestigiosa antropóloga Ludmila da Silva Catela, en el cual sitúa la obra y desarrolla las principales líneas de análisis esbozadas. Asimismo, posee una introducción donde la autora establece y da cuenta de su marco de análisis teórico. Se nutre -entre otros- de los aportes de Henry Rousso al recuperar su concepto de memoria en tanto organización del olvido, noción que enlaza con la formulación de "tradición selectiva" propuesta por Raymond Williams, que presupone que en determinada cultura ciertas construcciones discursivas son seleccionadas y acentuadas. De tal modo, se configura una 
narrativa hegemónica que significa el pasado a expensas de otros posibles relatos, no obstante -y aquí radica la apuesta de la autora- es posible que en determinadas coyunturas irrumpan otros modos de narrar el pasado que confrontan abiertamente con los relatos consolidados. Luego de la introducción se despliegan los cinco capítulos que forman parte de la trama argumentativa de la obra.

En el capítulo 1, "Denunciar el terrorismo de Estado", la autora se aboca al análisis del origen del nombre "La noche de los lápices". Presenta allí el vínculo entre esta denominación y otros acontecimientos con características de similar naturaleza. Asimismo, despliega los elementos que constituyen las configuraciones narrativas de los primeros testimonios que se suscitan, aún en dictadura, hasta aquellos que transcurren en el marco de la formación de la CONADEP.

En el capítulo 2 "Relato en la justicia" se propone examinar los testimonios que se desarrollan en el contexto del juicio a los excomandantes de las tres Juntas militares, que actuaron en el país desde Marzo de 1976. Destaca Sandra Raggio, que en dicho contexto cobra repercusión pública el testimonio de Pablo Díaz, relato que conformará la trama estructural que luego le irá otorgando sentidos y contenidos a la narrativa -más difundida y emblemática del terrorismo de Estado- en torno al secuestro-desaparición de jóvenes estudiantes de la ciudad de La Plata, en septiembre de 1976.

En el capítulo 3 "Explicar los hechos: del estrado judicial al libro" aborda la construcción narrativa desplegada en el libro escrito por los periodistas María Seoane y Héctor Ruiz Nuñez, quienes toman como guión de su relato el testimonio de Pablo Díaz. La autora, advierte aquí que la intención de los periodistas consistió en realizar una reconstrucción teleológica acerca del origen del acontecimiento, produciendo asimismo una explicación de los sucesos y en dicha argumentación le otorgaron una mayor entidad al contexto, quitando de ese modo agencia a los sujetos involucrados en él.

En el capítulo 4 "Del testimonio judicial al relato cinematográfico", la autora explora los sentidos que le son adjudicados a ese pasado, en relación sobre todo a los modos de representación de las experiencias límites, es decir, del horror. El relato testimonial de Pablo Díaz nuevamente se asume como el texto fundamental para estructurar el guión.

En el último capítulo "Las noche de los lápices. Los 'otros’ testigos de la historia", Sandra Raggio introduce uno de los elementos más sobresalientes de su obra. Los "otros" sobrevivientes dan testimonio de su experiencia y ponen en tensión las narrativas más vistas, leídas y escuchadas. Se bifurcan y ramifican así las narrativas en torno a las memorias del pasado, a sus sentidos y representaciones, haciéndose manifiestas así las disputas en la asignación que, desde el presente, se hacen de ellas. La autora logra dar cuenta de las controversias suscitadas entre los diversos modos de narrar y las luchas por el relato y la "verdad", tanto de la experiencia previa a la implantación del terrorismo de Estado como aquella que se desarrolla en los centros de detención clandestina.

En síntesis, es esta una obra orientada por el análisis y la reflexión acerca del pasado y el presente. Es una propuesta, también, para repasar las complejas tramas en las que se elaboran y anidan las memorias, tanto individuales como colectivas. Y es, por último, una invitación para conocer más de nuestra historia y memoria y poder dar cuenta, de un modo más acabado, de las operaciones que se generan entre ellas y nosotros. 